\title{
STUDI KELAYAKAN KELURAHAN KLOJEN SEBAGAI PUSAT WISATA KULINER HERITAGE KOTA MALANG
}

\author{
Putri Herlia Pramitasari \\ Dosen Prodi Arsitektur, Fak. Teknik Sipil dan Perencanaan, ITN Malang \\ e-mail: putri herlia@lecturer.itn.ac.id \\ Maria Istiqoma \\ Dosen Prodi Arsitektur, Fak. Teknik Sipil dan Perencanaan, ITN Malang \\ e-mail: maria istiqoma@lecturer.itn.ac.id \\ Mariza Kertaningtyas \\ Dosen Prodi Teknik Industri, Fak. Teknik Industri, ITN Malang \\ e-mail: mariza@fti.itn.ac.id
}

\begin{abstract}
ABSTRAK
Kelurahan Klojen terletak di pusat Kota Malang yang sangat strategis, dimana sekelilingnya terdapat pusat pemerintahan Kota Malang, hotel dan home stay, stasiun Kota Malang, sekolah, pasar tradisional, Rumah Sakit Umum, dan area perkantoran. Banyaknya potensi lokal, diantaranya usaha kuliner dengan beragam produk unggulan, serta peninggalan bangunan kolonial menjadikan Kelurahan Klojen dipertimbangkan sebagai salah satu kawasan ikon wisata kuliner tradisional khas Malang. Di sisi lain, belum terkonsepnya area kawasan usaha secara jelas dan matang, kualitas produk usaha dan upaya pemberdayaan masyarakat yang belum optimal, maka diperlukan pendampingan studi kelayakan pada Kelurahan Klojen khususnya kawasan Trunojoyo ini sekaligus sebagai upaya untuk menindaklanjuti Lomba Kampung Tematik - Festival Rancang Malang 2016, dimana telah berhasil masuk dalam 10 nominator terbaik. Metode penelitian fenomenologis atau eksploratori dilakukan melalui wawancara, observasi lapangan, dan pengumpulan data sekunder menggunakan metode pendekatan deskriptif analisis. Klojen Kuliner Heritage diangkat sebagai branding kawasan yang diharapkan dapat memperkuat citra kawasan sepanjang Jl. Trunojoyo hingga Jl. Dr. Sutomo menjadi area jajanan kuliner tradisional khas Malang dan wisata heritage. Strategi ini diupayakan melalui perbaikan dan peningkatan program fisik dan non-fisik kawasan yang diharapkan dapat memperkuat city branding Kota Malang sebagai Kota Wisata Kuliner Heritage.
\end{abstract}

Kata kunci : Klojen Kuliner Heritage, Kampung Tematik Malang, City Branding Malang

\section{ABSTRACT}

Klojen Village which is located in the center of Malang City is very strategic area surrounded by government centers of Malang, like: hotels, home stays, Malang City station, schools, traditional market, General Hospital, and office areas. The number of local potential, including culinary business with a variety of excellent products, as well as relics of colonial buildings 
make Klojen Village considered as one of the iconic area of traditional culinary of Malang. On the other hand, the concept of business area has not been clearly defined and mature, the quality of business products and efforts of community empowerment have not been optimally exposed, so it is needed to assist the feasibility study in Klojen Village, especially Trunojoyo area as well as an effort to follow up Thematic Village Competition - Festival Rancang Malang 2016 which has made it into the top 10 nominees. Methods of phenomenological or exploratory research was conducted through interviews, field observations, and secondary data collection employed the method of descriptive analysis approach. Klojen Culinary Heritage is appointed as a branding area which is expected to strengthen the image of the region along Jl. Trunojoyo to Jl. Dr. Sutomo become a traditional culinary of Malang and heritage tourism. This strategy is pursued through the repairment and improvement of physical and nonphysical program of the area which is expected to strengthen city branding of Malang as a City of Heritage Culinary Tour.

\section{Keywords : Heritage Culinary Klojen, Thematic Village Competition, Malang City Branding}

\section{PENDAHULUAN}

Kota Malang dikenal dengan semboyan Tri Bina Cita Kota Malang, yaitu sebagai Kota Pendidikan, Kota Pariwisata, dan Kota Industri. Kota Malang juga dikenal sebagai kota kuliner dengan beragam produk kuliner yang unik, menarik, dan penuh cita rasa. Oleh karena itu diperlukan strategi peningkatan city branding Kota Malang sebagai Kota Wisata, terutama Kota Wisata Kuliner Khas Malang.

Wilayah Kelurahan Klojen terletak di pusat Kota Malang yang strategis dan sangat potensial dijadikan sentra wisata kuliner Kota Malang. Pada kawasan ini banyak sekali tempat usaha kuliner maupun penjual makanan kaki lima yang sangat variatif di sepanjang Jl. Trunojoyo, Jl. Cokroaminoto hingga Jl. Dr. Soetomo yang terletak di Kelurahan Klojen. Di samping itu, wilayah Klojen juga kental dengan peninggalan Kolonial Belanda, sehingga dapat dioptimalkan menjadi daya tarik wisata lokal yang unik dengan mengusung konsep Kampung Wisata Kuliner Heritage.

Peraturan Daerah Kota Malang Nomor 4 Tahun 2011 tentang Rencana Tata Ruang Wilayah Kota Malang Tahun 2010 - 2030 menjelaskan bahwa kawasan Klojen merupakan kawasan perdagangan dan jasa, sehingga sangat tepat arahan pengembangan Kelurahan Klojen dijadikan sebagai sentra perdagangan dan jasa, khususnya sentra kuliner. Hal ini yang melatar belakangi Kelurahan Klojen mengikuti Lomba Kampung Tematik Malang - Festival Lomba Rancang Kota Malang 2016 hingga terpilih menjadi 10 Nominator terbaik. 
Permasalahan fisik dan non-fisik dijumpai pada kawasan objek studi, diantaranya terkait infrastruktur dan tata ruang kawasan yang kurang tertata dan tersistem dengan baik, serta kualitas dan promosi produk usaha yang kurang optimal.

Oleh karena itu, berdasakan permasalahan di atas diperlukan kajian studi kelayakan Kelurahan Klojen sebagai Pusat Wisata Kuliner Heritage untuk menggali potensi dan menentukan arahan pengembangan fisik dan non-fisik kawasan yang tepat untuk peningkatan city branding Kota Malang.

\section{TINJAUAN PUSTAKA}

Strategi peningkatan destinasi wisata lokal dibutuhkan untuk memperkuat city branding kota. Ries, A. dan Ries, L. (2003) dalam Wang, PH., Xing, Y-L, dan He, J-Y. (2016) memaparkan bahwa aspek penting dalam menciptakan city branding, yaitu keunikan kota, tema, memori, dan unsur simbolik kota. Terkait hal ini, aspek fisik bangunan dan kawasan berperan penting dan dominan untuk memperkuat Kelurahan Klojen sebagai sentra kuliner heritage di Kota Malang.

Di samping itu, diperlukan pengembangan aspek non-fisik kawasan melalui pengembangan ekonomi kreatif dan pemberdayaan masyarakat dalam pemenuhan keberhasilan dan keberlanjutan program pendampingan ini. Aspek penting dalam pengembangan industri kreatif, yaitu cerita, persepsi estetika, nilai (value), kreasi, dan pengalaman dalam menghasilkan empati untuk identitas budaya lokal (Hwang, S-H., et al: 2013). Oleh karena itu, strategi pengembangan aspek non-fisik kawasan diperlukan peran serta dan daya dukung lingkungan, sosial, dan budaya pada kawasan objek studi khususnya.

Hsu, C-H., et al (2014) menegaskan bahwa strategi desain produk juga penting dilakukan, mengingat menjadi salah satu komponen penting dalam pengembangan aspek budaya dan industri kreatif yang akan berpengaruh signifikan terhadap persepsi pengguna tentang inovasi. Oleh karena itu, sangat krusial dalam membuat inovasi suatu produk yang memiliki nilai budaya dan karakteristik lokal yang diminati pasar global untuk memperkuat city branding Kelurahan Klojen sebagai kawasan kuliner heritage sekaligus Kota Malang sebagai Kota Wisata.

Berdasarkan aspek-aspek di atas dapat disimpulkan bahwa dalam studi kelayakan ini perlu dikaji aspek fisik dan non-fisik kawasan objek studi sebagai langkah awal peningkatan destinasi wisata lokal dan city branding Kota Malang. 


\section{METODE PENELITIAN}

Metode penelitian dilakukan secara kualitatif dengan menggunakan metode naturalistik atau eksploratori. Metode pengumpulan data primer dilakukan melalui wawancara, diskusi dan sosialisasi, observasi lapangan, dan dokumentasi. Pengumpulan data sekunder dilakukan melalui studi literatur dan karya ilmiah.

Instrumen pengumpulan data menggunakan kamera, lembar observasi, dan media internet. Selanjutnya dilakukan analisis data dengan menggunakan metode deskriptif analisis, yaitu pemaparan kondisi dengan pendekatan historis-fenomenologis.

Aspek-aspek yang dianalisis mencakup studi kelayakan fisik dan nonfisik kawasan pada objek studi, yaitu:

a. Analisis fisik kawasan, terdiri dari kelengkapan fasilitas, kondisi fisik dan permasalahan yang dijumpai pada bangunan eksisting maupun kawasan objek studi

b. Analisis non-fisik kawasan, terdiri dari potensi, masalah, kekuatan, dan kelemahan kawasan objek studi.

Objek studi amatan terletak di sepanjang Jl. Trunojoyo hingga Jl. Dr. Sutomo, Kelurahan Klojen, Malang. Area lokasi bisa dilihat pada gambar berikut.

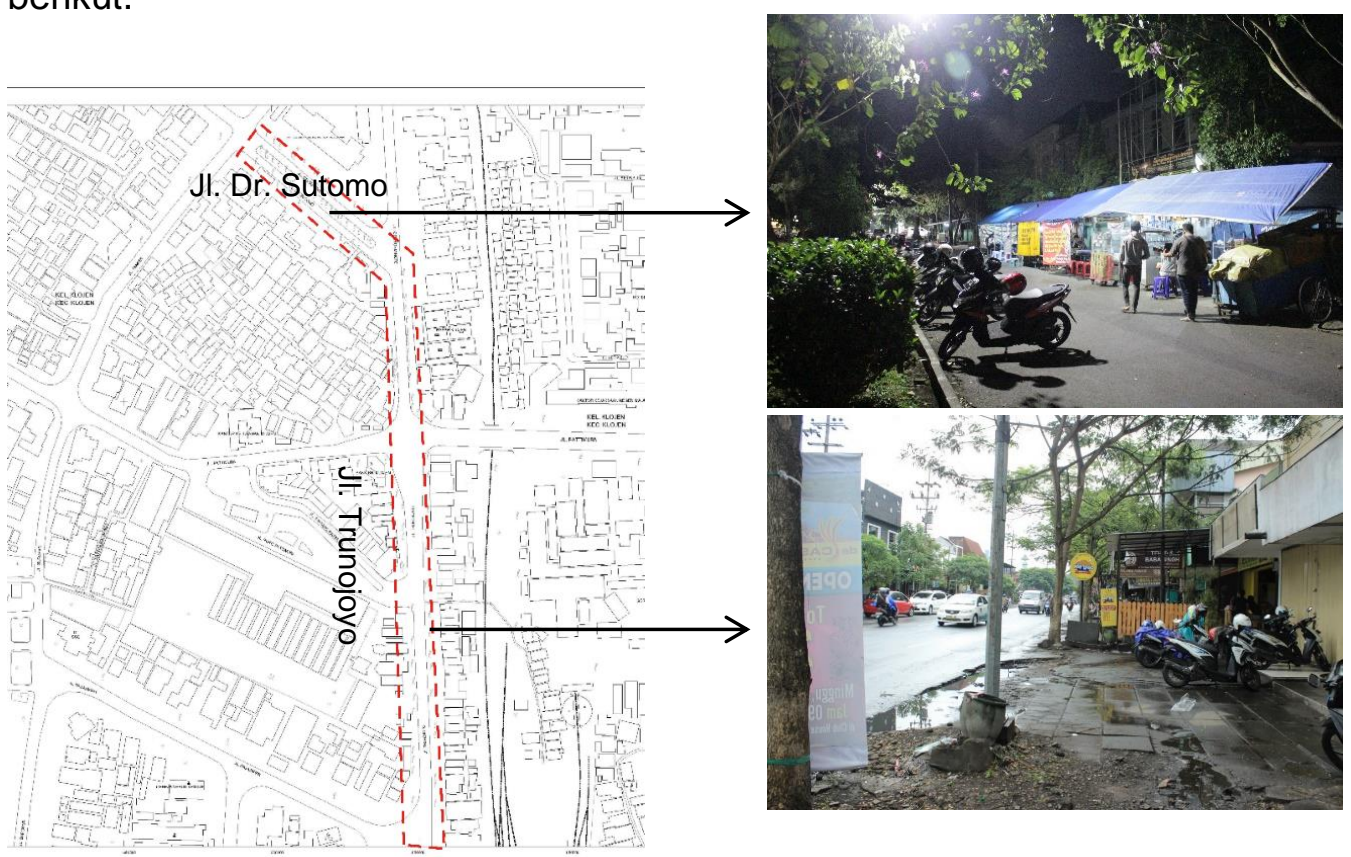

Gambar 1. Lokasi perencanaan kampung kuliner Heritage Sumber: Dokumentasi Pribadi (2017) 


\section{HASIL DAN PEMBAHASAN}

Kelurahan Klojen memiliki beragam potensi fisik dan non-fisik untuk dikembangkan menjadi salah satu destinasi wisata unggulan Kota Malang. Banyaknya peninggalan bangunan kolonial menjadi salah satu aset wisata lokal yang sangat potensial untuk dilestarikan. Banyaknya usaha kuliner khas Malang di Kelurahan Klojen juga menjadi aset wisata lokal untuk menarik wisatawan domestik maupun mancanegara.
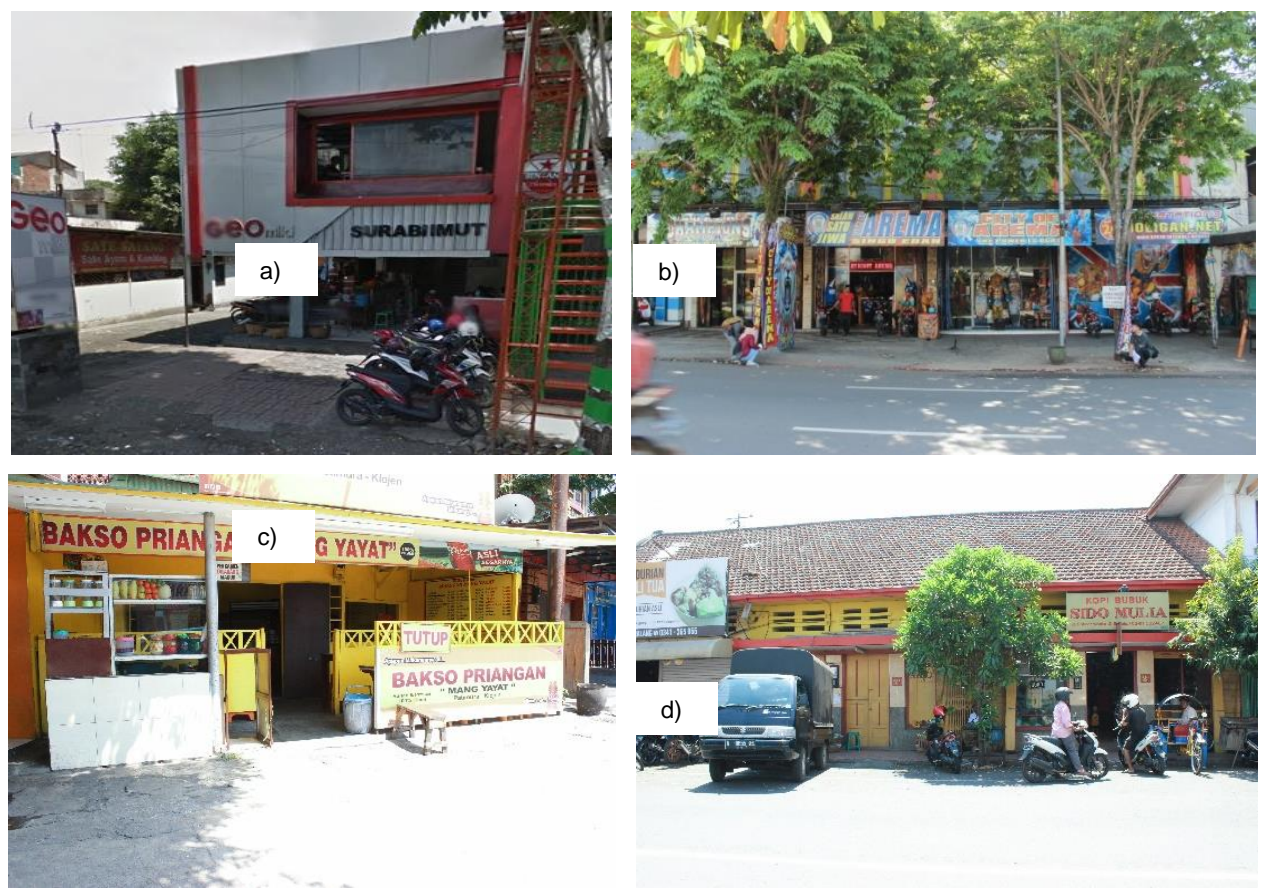

Gambar 2. Beberapa toko di sepanjang Jl. Trunojoyo;

a) Surabi Imut, b) City of Arema, c) Bakso Priangan, d) Kopi Sido Mulia Sumber: Dokumentasi Pribadi (2017)

\subsection{Analisis Fisik Kawasan}

Kelurahan Klojen dalam radius $1 \mathrm{~km}$ terletak pada jantung Kota Malang, dimana dekat dengan area kantor pemerintahan kota, sekolah, hotel, stasiun kota, pasar tradisional, area perkantoran swasta, klinik dan rumah sakit, bangunan peribadatan, dan aset wisata lokal lain.

Kelengkapan fasilitas didukung infrastruktur yang layak dan memadai; kemudahan transportasi; kelengkapan fungsi aktivitas, visual, dan utilitas bangunan sesuai kebutuhan pengguna; serta ketepatan tata ruang dan kawasan sesuai zonasi fungsi kawasan tentu dapat memperkuat dan meningkatkan citra kawasan untuk menarik minat wisatawan. 


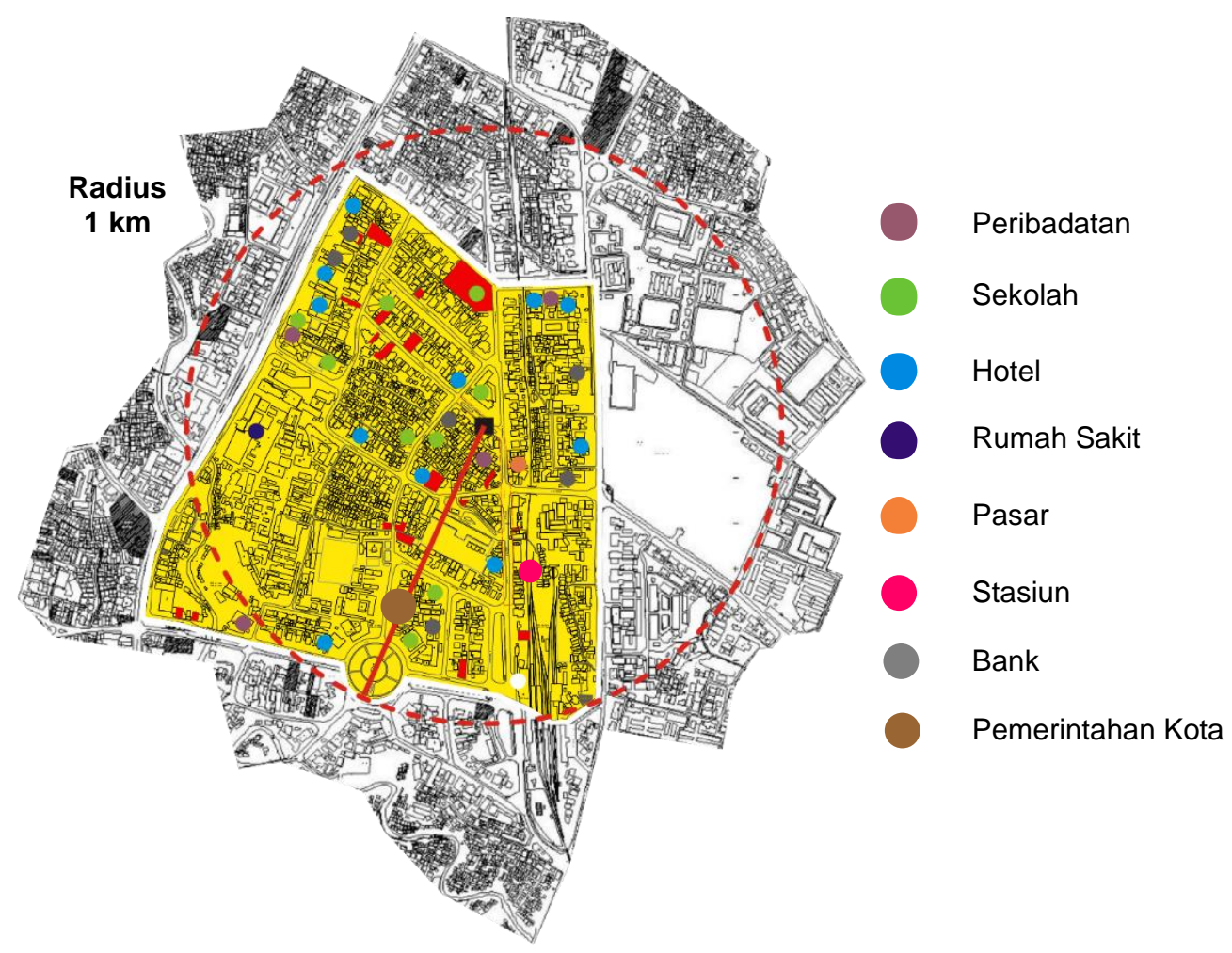

Gambar 3. Lokasi perencanaan kampung kuliner Heritage Sumber: Dokumentasi Pribadi (2017)

Keragaman area kuliner di sekitar kawasan perencanaan menjadi potensi utama dalam memperkuat citra kawasan. Banyaknya area kuliner tentu menjadi daya tarik bagi para wisatawan. Kuliner khas Malang dan kuliner legendaris lokal setempat menjadi potensi unggulan yang dapat dikembangkan untuk menarik minat wisatawan.

Keaslian bangunan heritage yang dapat mengingatkan kembali pada masa Malang tempo dulu juga turut menambah daya dukung citra kawasan. Fasade bangunan yang difungsikan sebagai tempat kuliner sebagian besar masih asli, namun tidak banyak pula originalitas fasade bangunan sepanjang kawasan objek studi tertutupi dengan papan nama yang dipasang sekadarnya dan kurang tertata dengan baik dan estetis sehingga cukup mengganggu tampilan visual fasade bangunan. 


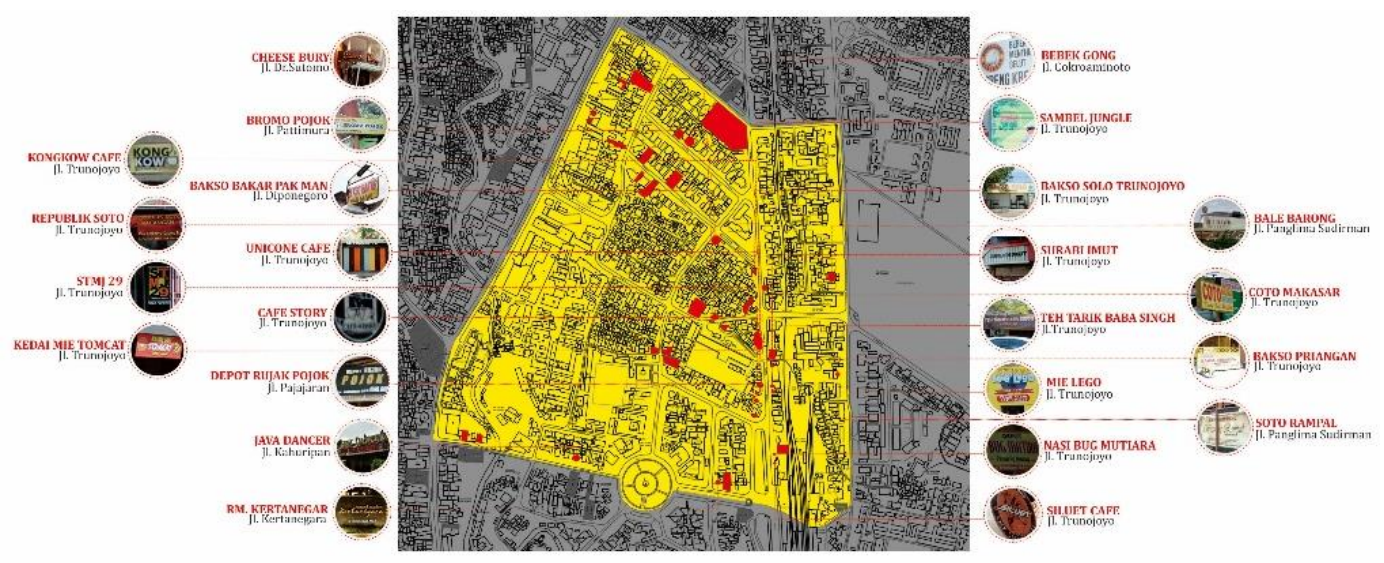

Gambar 4. Fasilitas tempat kuliner di Kelurahan Klojen, Kota Malang

Sumber: Analisis Penulis (2017)

Kawasan objek studi juga dikelilingi bangunan perkantoran, baik pemerintah maupun swasta. Fasade bangunan kantor pun masih banyak yang bernuansa Malang tempo dulu. Potensi pengunjung dari kalangan karyawan kantor pun tentu tinggi, terutama saat jam sarapan, maupun makan siang karena lokasi berdekatan dengan lokasi perencanaan.

Keaslian gedung kantor pada kawasan ini juga sebagian besar terjaga keasliannya, seperti Balaikota Malang, Kantor PLN, dan Bank Commonwealth yang merupakan bangunan cagar budaya Kota Malang. Gedung Bank Jatim, Skodam V/ Brawijaya pun merupakan peninggalan bangunan masa lampau yang tetap terawat dan terjaga keasliannya hingga kini.

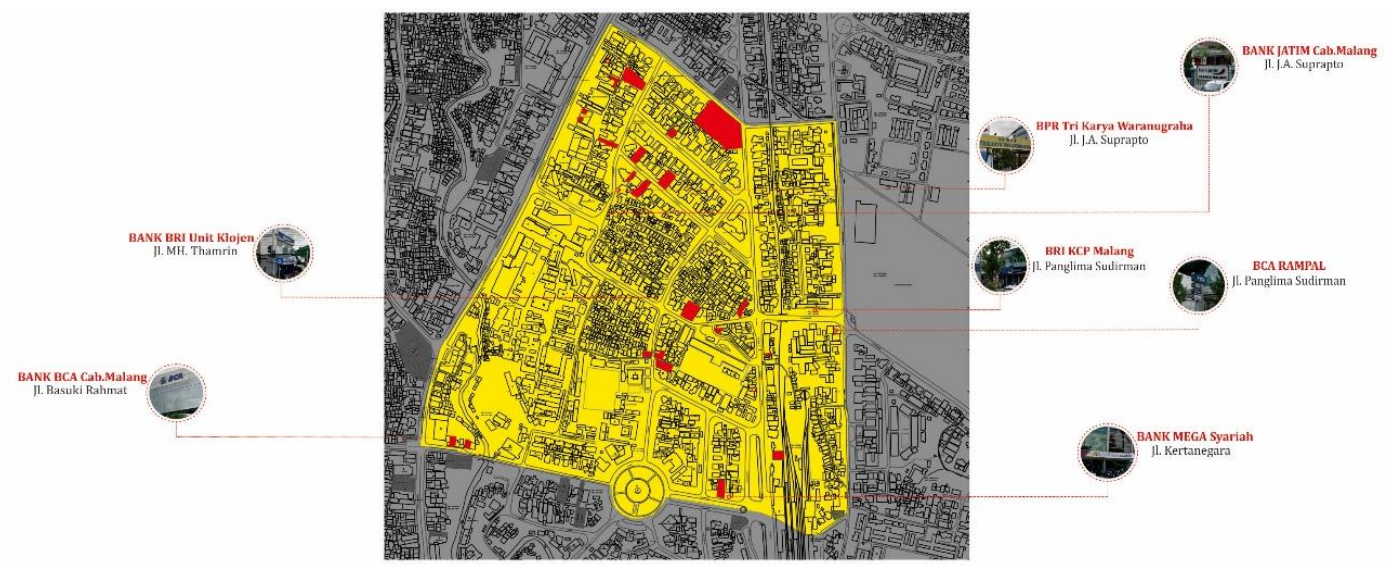

Gambar 5. Fasilitas perkantoran di Kelurahan Klojen, Kota Malang

Sumber: Analisis Penulis (2017) 
Bangunan sekolah di sekitar kawasan objek studi mayoritas didominasi bangunan Sekolah Menengah Pertama (SMP) dan Sekolah Menengah Atas (SMA) yang masih terjaga keaslian bangunannya. Bangunan sekolah Corjesu, Frateran, SMA Negeri 1, 3, dan 4 pun termasuk bangunan cagar budaya di Kota Malang. Konservasi bangunan sekolah dilakukan untuk menjaga keberlanjutan citra kawasan dengan tetap mempertahankan kondisi fisik bangunan asli sekolah.

Adanya fasilitas sekolah di sekitar lokasi tentu memberikan peluang besar untuk memperkuat citra kawasan yang akan diangkat. Kelurahan Klojen dan pihak sekolah dapat saling bekerjasama dan bersinergi melakukan berbagai program kegiatan yang dapat mewujudkan Kelurahan Klojen sebagai kawasan kuliner heritage.

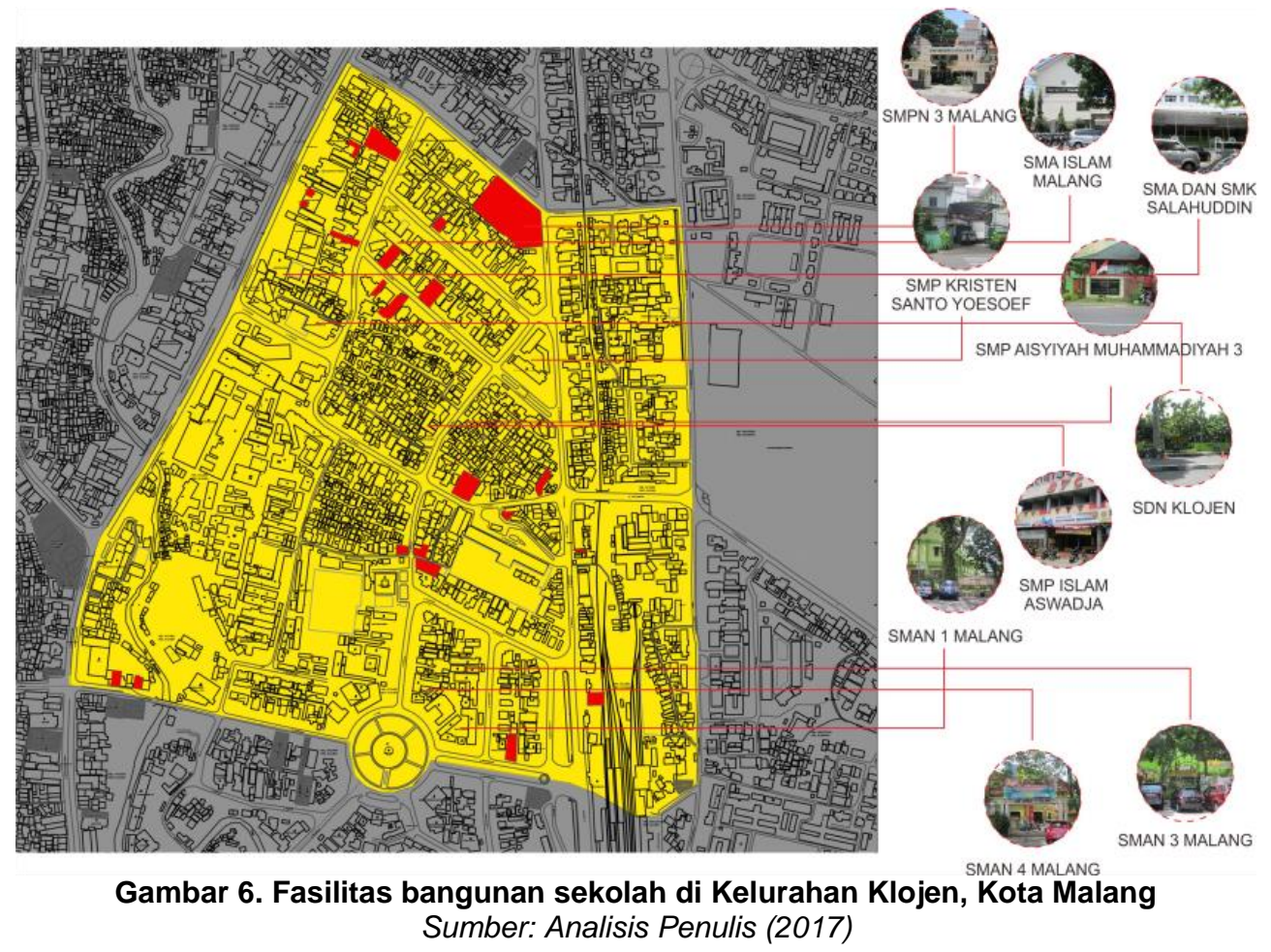

Fasilitas layanan publik, seperti rumah sakit, pasar, dan stasiun juga terwadahi pada kawasan ini. Sebagai contoh, Stasiun Kota Baru Malang merupakan salah satu bangunan cagar budaya, dimana hingga kini bangunan fisiknya dikonservasi dengan baik. Adanya kelengkapan fasilitas umum ini menjadi salah satu daya tarik untuk menarik minat para investor dan wisatawan dengan didukung infrastruktur yang layak dan nyaman bagi para pengunjung. 


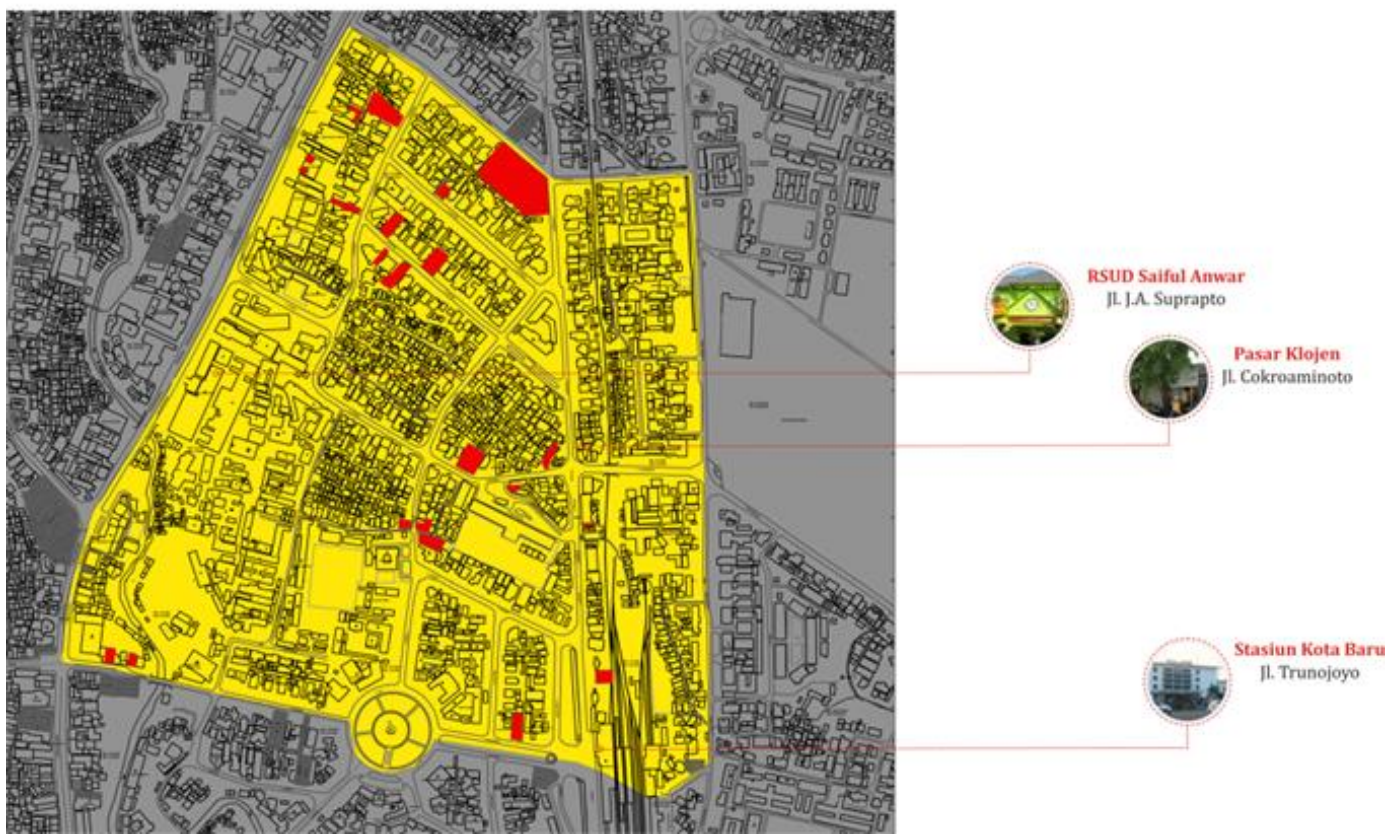

Gambar 7. Fasilitas umum (Rumah Sakit Umum, pasar, stasiun) di Kelurahan Klojen, Kota Malang

Sumber: Analisis Penulis (2017)

Fasilitas penginapan di kawasan sekitar lokasi perencanaan cukup mudah dijumpai dengan didukung akses pencapaian yang mudah dan infrastruktur yang layak. Adanya hotel di sekitar objek studi tentu sangat berdampak positif untuk memperkuat Kelurahan Klojen sebagai pusat wisata kuliner heritage. Beberapa bangunan hotel yang ada saat ini pun merupakan peninggalan bangunan heritage, seperti Hotel Regents Park, Hotel Tugu, dan Hotel Trio Indah yang masih terjaga keasliannya hingga saat ini.

Peluang kerjasama antara manajemen hotel dan Kelurahan Klojen dapat dijalin dengan melakukan kegiatan promosi satu sama lain ataupun rangkaian workshop, culinary art, dan strategi promosi lain yang dapat memperkuat citra kawasan objek studi. Hal ini tentu diharapkan dapat meningkatkan jumlah wisatawan menuju lokasi. 


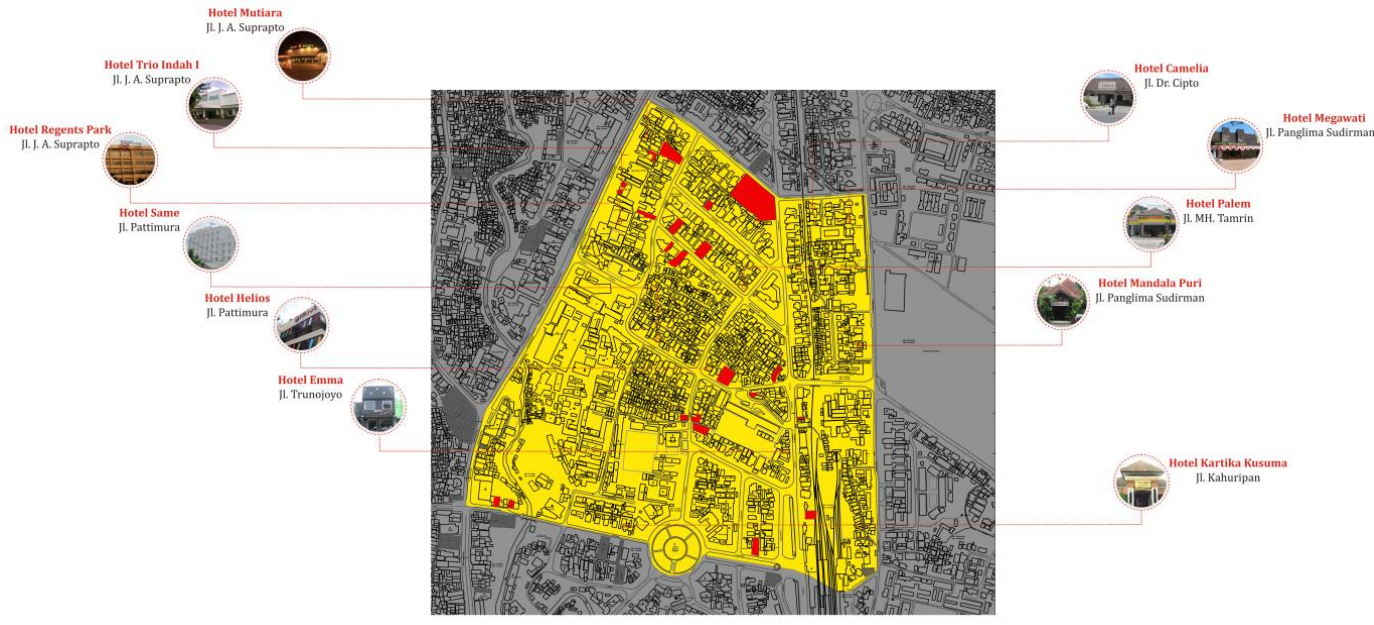

Gambar 8. Fasilitas hotel di Kelurahan Klojen, Kota Malang Sumber: Analisis Penulis (2017)

Sarana bangunan peribadatan juga cukup layak dan memadai dari lokasi objek studi, seperti Masjid dan Gereja. Ketersediaan fasilitas umum ini dengan didukung akses pencapaian yang mudah tentu akan membuat para pengunjung nyaman menuju tempat ibadah di lokasi terdekat.

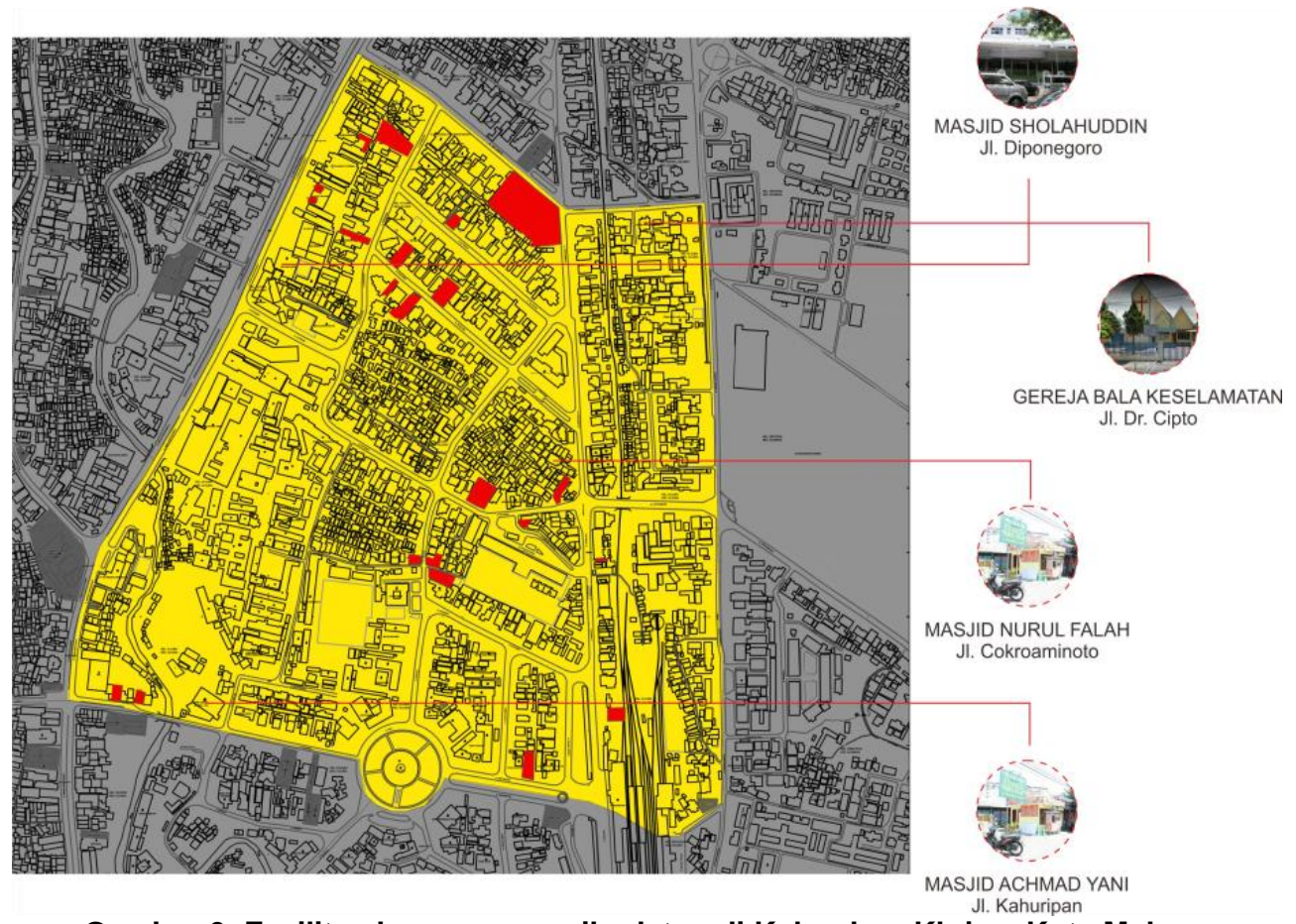

Gambar 9. Fasilitas bangunan peribadatan di Kelurahan Klojen, Kota Malang Sumber: Analisis Penulis (2017) 
Dari beragam fasilitas di atas, terdapat pula berbagai permasalahan yang muncul pada area kawasan objek studi, diantaranya:

a. Area Jl. Dr. Sutomo rawan tindak kejahatan dan maksiat, dimana didominasi pedagang kaki lima dari luar Kota Malang.

b. Saluran drainase rawan banjir (pertigaan Jl. Trunojoyo - Jl. Cokroaminoto - Jl. Dr. Sutomo).

c. Pedestrian (jalur pejalan kaki) sepanjang Jl. Trunojoyo banyak yang rusak.

d. Garis muka bangunan sepanjang Jl. Trunojoyo tidak beraturan.

e. Area kawasan usaha ekonomi kreatif kurang terarah dengan baik.

\subsection{Analisis Non-Fisik Kawasan}

Kelurahan Klojen memiliki jumlah penduduk yang cukup banyak sebesar $85 \mathrm{jiwa} / \mathrm{Ha}$. Di wilayah ini memiliki jumlah penduduk perempuan yang lebih banyak di bandingkan penduduk laki-laki. Dari jumlah penduduk di wilayah Kelurahan Klojen memiliki 4287 jiwa penduduk yang berada pada usia produktif (usia 15-64 tahun). Penduduk di wilayah ini juga sangat berpendidikan dengan mayoritas latar belakang pendidikan SMP/ SMA. Mayoritas penduduk juga bermata pencaharian di bidang jasa dan perdagangan. Kelurahan Klojen juga telah mensosialisasikan pengembangan kampung kuliner ini pada LPMK (Lembaga Pemberdayaan Masyarakat Kelurahan), RT dan RW setempat, BKM/ LKM, Tim penggerak PKK Kelurahan, Karang Taruna, Kader Lingkungan, Kader Posyandu, komunitas, dan sebagainya yang sangat mendukung terwujudnya program ini dan kedepannya terus berkelanjutan.

Di sisi lain terdapat permasalahan non-fisik kawasan, diantaranya:

a. Manajemen parkir liar di area Jl. Dr. Sutomo.

b. Kualitas produk usaha ekonomi kreatif belum optimal.

c. Jalinan dengan mitra terkait kurang optimal.

Dari berbagai permasalahan fisik dan non-fisik yang muncul pada objek studi, terdapat potensi, kekuatan, dan kelemahan pada kawasan yang dirangkum pada tabel berikut.

Tabel 1.

Analisis Potensi, Kelebihan, dan Kekurangan

\begin{tabular}{|c|c|}
\hline Aspek & Keterangan \\
\hline Potensi & $\begin{array}{l}\text { a. Mata pencaharian penduduk mayoritas wirausaha bidang } \\
\text { jasa, usia produktif (5-65 tahun), berlatar pendidikan minimum } \\
\text { SMP/ SMA, dominasi jenis kelamin perempuan. } \\
\text { b. Produk unggulan Kelurahan Klojen, yaitu Surabi imut (RW.3), } \\
\text { Kopi (Sido Mulia, Sido Mukti - RW. 4), STMJ, Jagung Bakar, } \\
\text { Bakso, Pecel Klojen, Jajanan Pasar, Atribut arema (RW.7), } \\
\text { dsb. }\end{array}$ \\
\hline
\end{tabular}




\begin{tabular}{|c|c|}
\hline Aspek & Keterangan \\
\hline Kekuatan & $\begin{array}{l}\text { a. Lokasi strategis (pusat kota), yaitu radius } 0.5-1 \mathrm{~km} \text { dekat } \\
\text { dengan pusat pemerintahan Kota Malang, } 13 \text { hotel dan home } \\
\text { stay, stasiun Kota Malang, sekolah, pasar tradisonal, RSU } \\
\text { Saiful Anwar, dan area perkantoran. } \\
\text { b. Destinasi wisata unggulan Kota Malang dan bersinergi } \\
\text { dengan aset wisata lokal lain; Pasar Bunga dan Pasar Burung } \\
\text { Splendid, Edupark (ex. Senaputra), Tarekot (Taman Rekreasi } \\
\text { Kota), Taman Alun-alun Tugu, Taman Pintar Trunojoyo. } \\
\text { c. Banyak peninggalan bangunan kolonial Belanda berpotensi } \\
\text { dijadikan sebagai wisata heritage. } \\
\text { d. Aksesibilitas menuju lokasi sangat mudah. } \\
\text { e. Sistem transportasi mudah dan infrastuktur nyaman. }\end{array}$ \\
\hline Kelemahan & $\begin{array}{l}\text { a. Potensi macet. } \\
\text { b. Kekurangan lahan parkir. }\end{array}$ \\
\hline
\end{tabular}

Sumber: Analisis Penulis (2017)

Banyaknya potensi dan kekuatan daya dukung lingkungan, sosial, ekonomi, dan budaya dari kawasan ini, diharapkan dapat disusun berbagai skema solusi permasalahan secara konkret untuk mencegah dan mengurangi permasalahan fisik dan non-fisik kawasan.

Tabel 2.

Skema Solusi Permasalahan

\begin{tabular}{|c|c|}
\hline Masalah & Solusi \\
\hline \multicolumn{2}{|c|}{ Skema Solusi Permasalahan Fisik Kawasan: } \\
\hline $\begin{array}{l}\text { a. Area Jl. Dr. Sutomo rawan } \\
\text { tindak kejahatan dan } \\
\text { maksiat, dimana didominasi } \\
\text { pedagang kaki lima dari luar } \\
\text { Kota Malang }\end{array}$ & $\begin{array}{l}\text { a. Usulan konsep desain ruang terbuka di } \\
\text { sepanjang kawasan Jl. Trunojoyo hingga JI. } \\
\text { Dr. Sutomo untuk diarahkan menjadi ruang } \\
\text { terbuka publik yang interaktif, edukatif, } \\
\text { rekreatif, dan inovatif. }\end{array}$ \\
\hline & $\begin{array}{l}\text { b. Simulasi warung percontohan pada Jl. Dr. } \\
\text { Sutomo sebagai sentra kuliner. }\end{array}$ \\
\hline & $\begin{array}{l}\text { c. Usulan program kegiatan secara kolaboratif; } \\
\text { baik program kegiatan berbasis peningkatan } \\
\text { ekonomi kreatif dan pemberdayaan } \\
\text { masyarakat lokal. }\end{array}$ \\
\hline & $\begin{array}{l}\text { d. Penertiban kebijakan secara struktural dan } \\
\text { non-struktural. }\end{array}$ \\
\hline $\begin{array}{l}\text { b. Saluran drainase minim } \\
\text { (pertigaan Jl. Trunojoyo - Jl. } \\
\text { Cokroaminoto - Jl. Dr. } \\
\text { Sutomo) }\end{array}$ & $\begin{array}{l}\text { Usulan perbaikan sistem saluran drainase } \\
\text { berbasis konsep green technology. }\end{array}$ \\
\hline $\begin{array}{l}\text { c. Pedestrian banyak yang } \\
\text { rusak }\end{array}$ & $\begin{array}{l}\text { Perbaikan jalur pedestrian menjadi lebih } \\
\text { fungsional dan inovatif agar tidak dijadikan area } \\
\text { parkir kendaraan dan tempat berjualan. }\end{array}$ \\
\hline
\end{tabular}




\begin{tabular}{ll}
\hline \multicolumn{1}{c}{ Masalah } & \multicolumn{1}{c}{ Solusi } \\
\hline $\begin{array}{l}\text { d. Garis muka bangunan tidak } \\
\text { beraturan }\end{array}$ & $\begin{array}{l}\text { Penertiban garis sempadan bangunan oleh } \\
\text { dinas pemerintah terkait. }\end{array}$ \\
\hline $\begin{array}{l}\text { e. Area kawasan usaha } \\
\text { ekonomi kreatif kurang } \\
\text { terarah dengan baik }\end{array}$ & $\begin{array}{l}\text { Penataan sentra kawasan usaha ekonomi } \\
\text { kreatif melalui fragmentasi produk dan inovasi } \\
\text { produk. }\end{array}$ \\
\hline \multicolumn{1}{c}{ Skema Solusi Permasalahan } & Non-Fisik Kawasan: \\
\hline $\begin{array}{l}\text { a. Manajemen parkir liar di area } \\
\text { J. Dr. Sutomo }\end{array}$ & $\begin{array}{l}\text { Penertiban kebijakan lahan parkir dan } \\
\text { penyediaan lahan parkir yang memadai. }\end{array}$ \\
$\begin{array}{ll}\text { b. Kualitas produk usaha } \\
\text { ekonomi kreatif belum } \\
\text { optimal }\end{array}$ & $\begin{array}{l}\text { a. Peningkatan kualitas produk usaha ekonomi } \\
\text { kreatif. }\end{array}$ \\
& $\begin{array}{l}\text { b. Peningkatan program pemberdayaan } \\
\text { masyarakat. }\end{array}$ \\
& $\begin{array}{l}\text { c. Peningkatan strategi promosi. } \\
\text { d. Pemberian label produk usaha ekonomi } \\
\text { kreatif. }\end{array}$ \\
\hline $\begin{array}{l}\text { c. Jalinan dengan mitra terkait } \\
\text { kurang optimal }\end{array}$ & $\begin{array}{l}\text { Peningkatan media promosi dan kerjasama } \\
\text { dengan para stakeholders. }\end{array}$ \\
\hline
\end{tabular}

Sumber: Analisis Penulis (2017)

\section{KESIMPULAN}

Kelurahan Klojen, khususnya kawasan sepanjang Jl. Trunojoyo hingga JI. Dr. Sutomo sangat potensial dikembangkan menjadi sentra wisata kuliner heritage sebagai salah satu destinasi wisata unggulan Kota Malang. Hal ini sebagai upaya memperkuat city branding Kota Malang sebagai Kota Wisata. Strategi perbaikan dan peningkatan program fisik dan non-fisik kawasan juga diusulkan untuk menyelesaikan permasalahan yang ada agar bersinergi dengan program pemerintah kota dan tetap berkelanjutan. Studi selanjutnya dapat dikembangkan berupa perencanaan desain fisik maupun non-fisik kawasan hingga implementasi produk terapan dari desain yang dibuat secara periodik.

\section{DAFTAR PUSTAKA}

Hsu, C-H., Fan, C-H., Lin, J-Y., dan Lin, R. 2014. An Investigation on Consumer Cognition of Cultural Design Products. Bulletin of JSSD - The Science of Design. 60 (5): 39-48.

Hwang, S-H., Tsai, I-C., Mitsuhashi, T., dan Miyazaki, K. 2014. The Application of Kano Model on Exploring The Attractive Attributes of Community Culture Products. Bulletin of JSSD - The Science of Design. 61 (1): 27-36.

Peraturan Daerah Kota Malang Nomor 4 Tahun 2011 tentang Rencana Tata Ruang Wilayah Kota Malang Tahun 2010-2030. http://peraturan.go.id/perda/kotamalang-nomor-4-tahun-2011-tahun-2011.html. Diakses tanggal 1 Juli 2017. 
Wang, P-H., Xing, Y-L, dan He, J-Y. 2016. A Study of The Planning and Creation of Shopping District Image - The Case of The Ruins of St. Paul Tourist Site. Bulletin of JSSD - The Science of Design. 63 (1): 31-40. 